\title{
Introducing Physics of Failure Considerations in the Electrical Machines Design
}

\author{
Vincenzo Madonna $^{1}$, Paolo Giangrande ${ }^{1}$, Michael Galea ${ }^{1,2}$ \\ ${ }^{1}$ PEMC Group, University of Nottingham, Nottingham, NG72RD, UK, Vincenzo.Madonna1@nottingham.ac.uk \\ ${ }^{2}$ School of Aerospace, University of Nottingham Ningbo China, Ningbo 315100, China
}

\begin{abstract}
For continuous-duty applications, electric motors are conventionally designed to experience a hot-spot temperature below their insulation thermal class. When frequent overloads are required, a safety temperature-margin is considered at the machine's design stage, so that the insulation is not thermally overstressed. This procedure leads to an increment of the machine's size, with a consequent power density reduction. Indeed, lower thermal loadings are obtained by decreasing the winding current density by e.g. increasing the equivalent cross-sectional area of conductors. For some applications, it is possible to avoid the "over-engineering", but the reliability level might be compromised. This work addresses the subject of thermal overload capability in electrical machines, combining elements of thermal analysis, reliability and physics of failure. A novel design methodology is introduced and validated by means of thermal accelerated lifetime tests on winding specimens. The proposed approach is used for redesigning a brushless DC motor achieving excellent results in terms of power density boost.
\end{abstract}

Index Terms - Accelerated Aging Tests, BLDC, Insulating Materials, Organic Insulation, Physics of Failure, Thermal analysis, UAV.

\section{INTRODUCTION}

A performance-limiting factor in electrical machines (EMs) is the high temperature [1-3]. In fact, the torque-producing capability is constrained by the maximum temperature at which some of its components can operate. In a permanent magnet $(\mathrm{PM})$ - free EM, the most temperature-susceptible part is the insulation system. On the other hand, in PM machines (particularly those adopting neodymium-based PMs), the magnets are also critical components [4]. They might be subject to performance derating and in some cases to permanent demagnetization, caused by uncontrolled temperature-overload situations [5-7].

The maximum EM operating temperature is defined by the thermal class of its weakest insulating sub-system. In low voltage random wound EMs, the latter generally represented by the magnet wire, since it is insulated by a thin organic enamel layer (i.e. Type I insulation) [8]. Therefore, evaluating the lifetime of the magnet wire insulation corresponds to estimate the EM's lifetime. This concept is valid if other failure modes (e.g. mechanical faults, PMs demagnetization etc.) are less likely to occur (i.e. lower probability of failure) $[9,10]$. At the same time, if an EM is demanded to reliably run for a stated number of cycles / years, then, understanding its insulation's aging phenomenology allows to improve the

This work was funded by the INNOVATIVE doctoral programme. The INNOVATIVE programme is partially funded by the Marie Curie Initial Training Networks (ITN) action (project number 665468) and partially by the Institute for Aerospace Technology (IAT) at the University of Nottingham.

This work was also partially funded by the University of Nottingham's Propulsion Futures Beacon through Grant PF42.

This work was also supported by the Ningbo 3315 Innovation Team Scheme under Grant 2018A-08-C. machine design process through the adoption of suitable solutions for avoiding the "over-engineering" [11].

According to the premises, this paper combines notions of thermal analysis, reliability and insulation's physics of failure, aiming at refining the design procedure of low voltage random wound EMs. An outer rotor PM machine, used for propelling a lightweight unmanned aerial vehicle (UAV), is chosen as study-case. From the application's specifications, two machines are conceived: 1) Prototype A whose design follows a conventional viewpoint and 2) Prototype B where reliability and physics of failure considerations are accounted for at the design stage. Emphasis is given to the power density enhancement reached by Prototype B thanks to the proposed design approach. Finally, accelerated thermal aging tests are performed on custom-designed coils' specimens for 1) confirming the effectiveness of the proposed design methodology and 2) assessing the prototype capability in meeting the reliability requirements.

\section{APPLICATION DESCRIPTION AND PROTOTYPES DESIGN}

The analysed PM machine is needed for propelling a lightweight radio-controlled UAV, which was designed and manufactured within the authors' academic institution. The choice of using an outer rotor (outrunner) brushless DC (BLDC) motor is quite common for the application at hand [12]. Indeed, the BLDC topology can develop higher power density compared with conventional brushed DC motors, while keeping relatively simple both power electronics and control strategy [13].

The EM should be able to deliver a continuous mechanical power of $300 \mathrm{~W}$ at $10,000 \mathrm{rpm}$. For UAVs (and aircraft in general), the most challenging flying-phases are the take-off and climbing. During these stages, the propulsion system must produce a superior thrust level with respect to e.g. cruise and descent flying-phases [14-16]. For the considered UAV, the propulsion EM must provide a peak power of $870 \mathrm{~W}$ for up-to $60 \mathrm{~s}$ in each mission according to the profile reported in Fig. 1. Further, the EM should safely operate for 5000+ missions, with a probability of failure below $1.5 \%$.

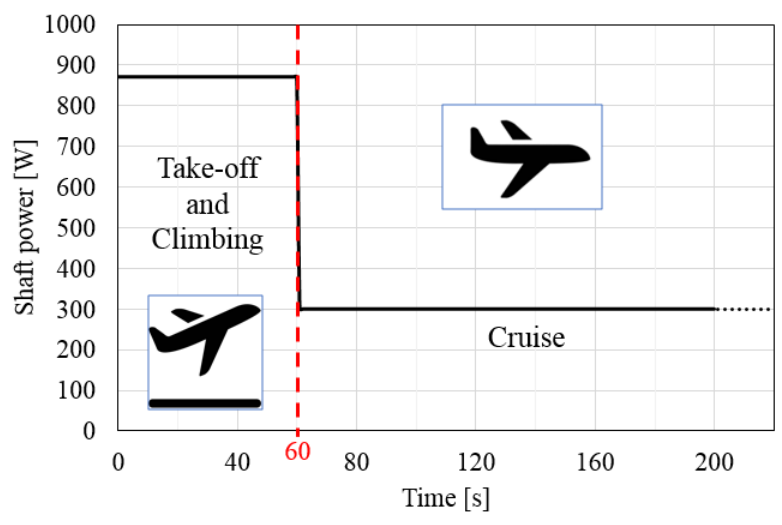

Fig. 1 UAV mission profile and required power at the EM shaft. 
A major constraining factor in light UAVs (and mobile applications in general) is the energy storage system [17-19]. In fact, capacity (i.e. energy storage rating in Ah), voltage level (i.e. number of series-connected cells) and overload capability of the battery pack play a crucial role. In the application under study the available energy storage system is a $5000 \mathrm{mAh}$ (rated capacity) lithium-polymer battery with 6 cells (i.e. DC link $\approx 22.2 \mathrm{~V}$ ) and an overload capability of $30 \mathrm{C}$, resulting in 150 A maximum current.

\section{A. Design of Prototype A}

Prototype A is designed for meeting the application constraints in both rated and overload conditions, whereas its hot-spot temperature is always below the magnet wire thermal class (i.e. $200{ }^{\circ} \mathrm{C}$ ) [20]. As expected, such design procedure will lead to an over-engineered machine that will be immune to excessive thermal aging (i.e. 20,000+ hours lifetime) and will naturally comply with the reliability specification.

An outer rotor BLDC motor is selected and throughout a benchmark exercise, its geometrical dimensions are chosen by re-scaling those of a commercially available motor, which is shown in Fig. 2. The machine features a 12 slots / 14 poles configuration with concentrated windings, which allow for a higher slot copper fill factor [21]. For complying with the limited DC link voltage, the winding is delta-connected with two parallel branches $[22,23]$. The main design quantities of Prototype A are listed in Table I.

From Fig. 2, it can be observed that the machine has open end caps on both drive- and non-drive ends. This provides excellent air flow through the machine stator (comparable with forced air cooling), enhanced by the propeller's induced turbulence.

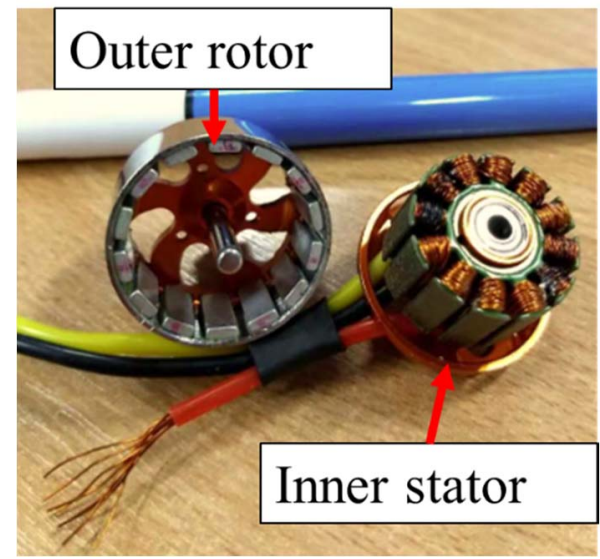

Fig. 2 Outer rotor BLDC motor.

TABLE I PROTOTYPE A DESIGN PARAMETERS

\begin{tabular}{lll}
\hline \hline Design parameter & Quantity & Unit \\
\hline Base speed, $\mathrm{n}$ & 10,000 & $\mathrm{rpm}$ \\
\hline Pole pairs, $\mathrm{p}$ & 7 & - \\
\hline Slot number, $\mathrm{Q}$ & 12 & - \\
\hline Windings layout & Conc. & - \\
\hline Phases & 3 & - \\
\hline Turns per coil, $\mathrm{n}_{\mathrm{t}}$ & 10 & - \\
\hline Parallel paths & 2 & - \\
\hline Copper slot fill factor, $\mathrm{ff}_{\mathrm{W}}$ & 42 & $\%$ \\
\hline Axial length, $\mathrm{L}$ & 30 & $\mathrm{~mm}$ \\
\hline Armature diameter & 40 & $\mathrm{~mm}$ \\
\hline \hline
\end{tabular}

Finite Elements (FE) simulations have been run for determining the machine's performance using the commercial software ANSYS ${ }^{\circledR}$ Maxwell. The flux density map and magnetic field lines for both rated and overload conditions are shown in Fig. 3 a) and b) respectively, whilst the instantaneous torque as well as the average torque plots are reported in Fig. 4 for the examined operating operations.

A considerable torque ripple, caused by the delta-connected winding (i.e. presence of $3^{\text {rd }}$ order field harmonics), is observable in Fig. 4. By multiplying the (average) torque with the rotational speed (i.e. 10,000 rpm), it can be easily verified that the power constraints (see Fig. 1) are met.

The rated torque is generated by feeding the windings with a current density $J$ of $4.2 \mathrm{~A} / \mathrm{mm}^{2}$, while $12 \mathrm{~A} / \mathrm{mm}^{2}$ are needed for producing the peak torque. These current density values are highly conservative for a "forced air-cooled" machine, especially considering the short time-period overload of the application under study (i.e. $60 \mathrm{~s}$ ) $[24,25]$. Thus, it is easy to verify that the hot-spot temperature is lower than the insulation's thermal class in every operating condition.

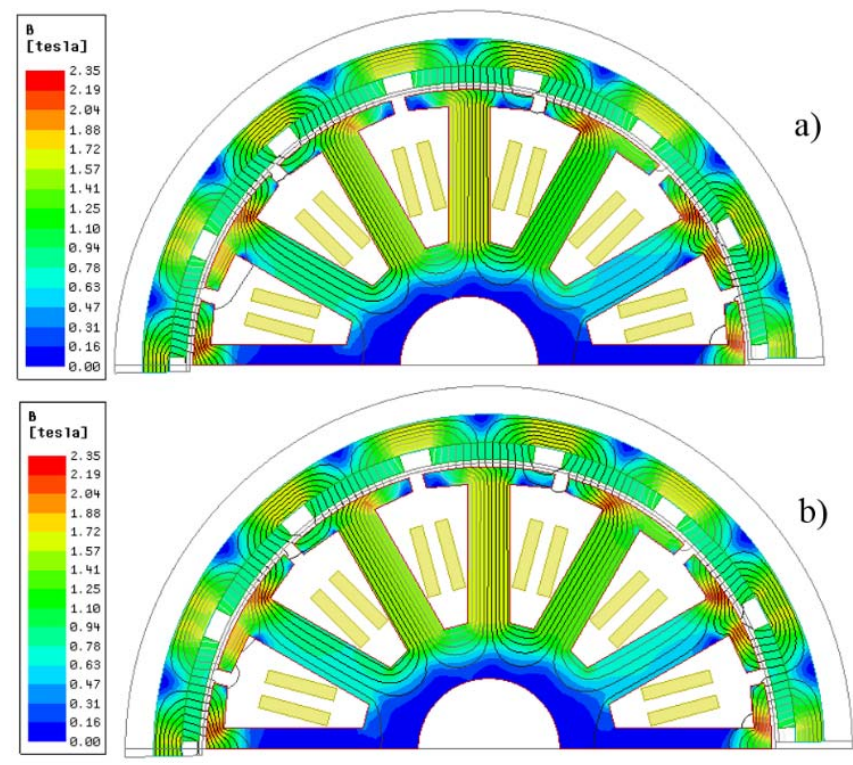

Fig. 3 Prototype A magnetic flux density map and field lines at base speed for a) rated and b) overload conditions.

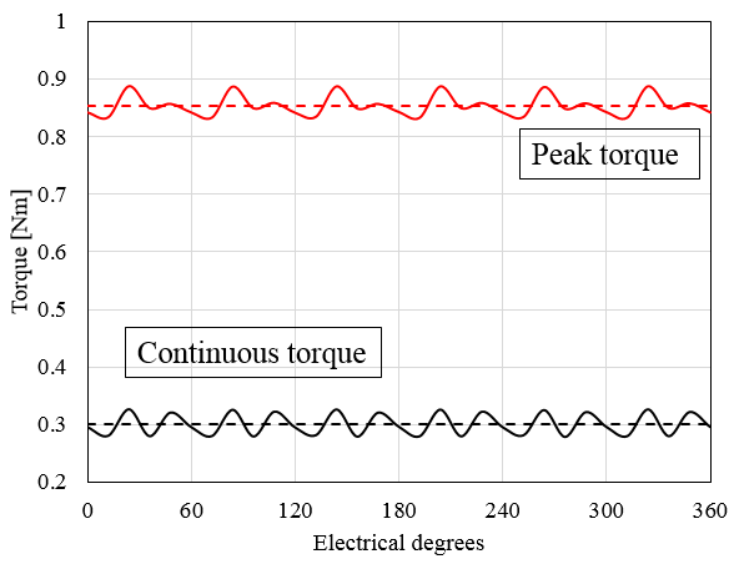

Fig. 4 Peak and continuous torque for Prototype A at base speed.

\section{B. Design of Prototype $B$}

As for Prototype A, the operating points at rated and overload conditions (see Fig. 1) are accounted for designing Prototype B. However, the new machine is conceived for working above the magnet wire thermal class (i.e. $200{ }^{\circ} \mathrm{C}$ ), while meeting the reliability requirement. The radial geometry of Prototype B is kept identical to the one of Prototype A, whereas its axial length is shortened from 30 to $20 \mathrm{~mm}$, allowing a compact design. Since a shorter machine reveals a lower per-turn back EMF, the turns number of Prototype B is modified according to the available DC link voltage. After a sensitivity analysis, based on electromagnetic 
FE simulations, the selected number of turns per coil results equal to 13. Apart from $L$ and $n_{t}$, all the remaining design parameters have been kept equal to those reported in Table I.

Due to the aforementioned changes (i.e. axial length and turns number), the power requirements are fulfilled by increasing the phase current (compared to Prototype A case), hence, enhanced current densities are achieved. In particular, $6.3 \mathrm{~A} / \mathrm{mm}^{2}$ and $18.9 \mathrm{~A} / \mathrm{mm}^{2}$ (for up-to $60 \mathrm{~s}$ ) are the current density values during rated and overload operations respectively. The latter value is extremely demanding in terms of thermal management. Therefore, further verifications are necessary for assessing the reliability constraint, which are carried out in the next sections.

The results from the FE simulations are reported in Fig. 5 for what concerns the magnetic field distribution and in Fig. 6 for the instantaneous torque plots in both rated and overload conditions. Observing Fig. 5, a slightly higher saturation level, with respect to Prototype A, is reached (cfr. Fig. 3). Nonetheless, Prototype B is able to develop the required torque (power) as can be seen in Fig. 6 . The ratio between current density in overload and rated conditions (i.e. overload factor) is equal to 2.86 for Prototype A and 3 for Prototype B. Indeed, because of the magnetic saturation, Prototype B requires a higher current overload factor for achieving the peak power (note that slot copper fill factor, and magnet wire are kept identical for both prototypes).

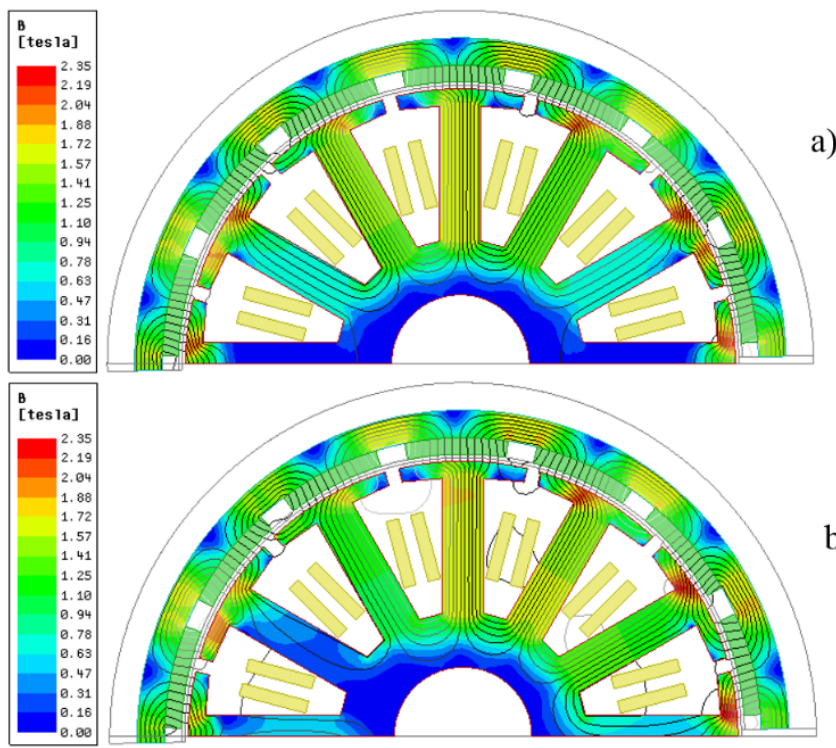

Fig. 5 Prototype B magnetic flux density map and field lines at base speed for a) rated and b) overload conditions.

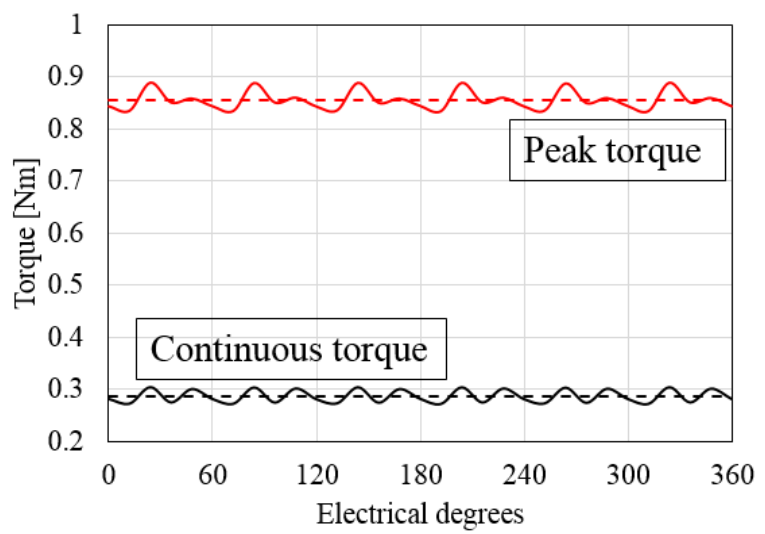

Fig. 6 Peak and continuous torque for Prototype B at base speed.

\section{THERMAL ANALYSIS}

In order to verify Prototype B's thermal performance, a lumped parameter thermal network (LPTN), which considers axial and radial heat transfers, is built in Matlab ${ }^{\circledR}$ Simscape environment. Its layout is shown in Fig. 7. Each active node consists of a heat source, whose power magnitude is calculated according to the EM power loss distribution, and a thermal mass (i.e. capacitance) necessary for accounting transient temperatures [26, 27]. The computation of thermal elements within the LPTN follows the standard procedure already presented by the authors, and reported in [28-30], which for brevity reasons is not repeated here.

As the hot-spot temperature is expected to be located in the winding, the rotor has not been included in the LPTN. This assumption is valid since the heat produced within the stator is mainly transferred to the ambient air due to the open end caps arrangement. Also, the solid power losses (i.e. core and $\mathrm{PMs}$ ) within the rotor are one order of magnitude lower than those of the stator as can be observed in Fig. 8, where the solid losses per unit mass are computed using the commercial software MotorCAD ${ }^{\circledR}$. Furthermore, given the EM arrangement (i.e. outrunner) and the relatively high rotational speed, the loss generated within the rotor are dissipated towards the ambient air through convection.

The stator surfaces considered in the computation of forced convection coefficients are shown in Fig. 9. For the sake of clarity, the 3D view of the machine (including the front end cap), and the direction of the airflow is depicted in Fig. 10.

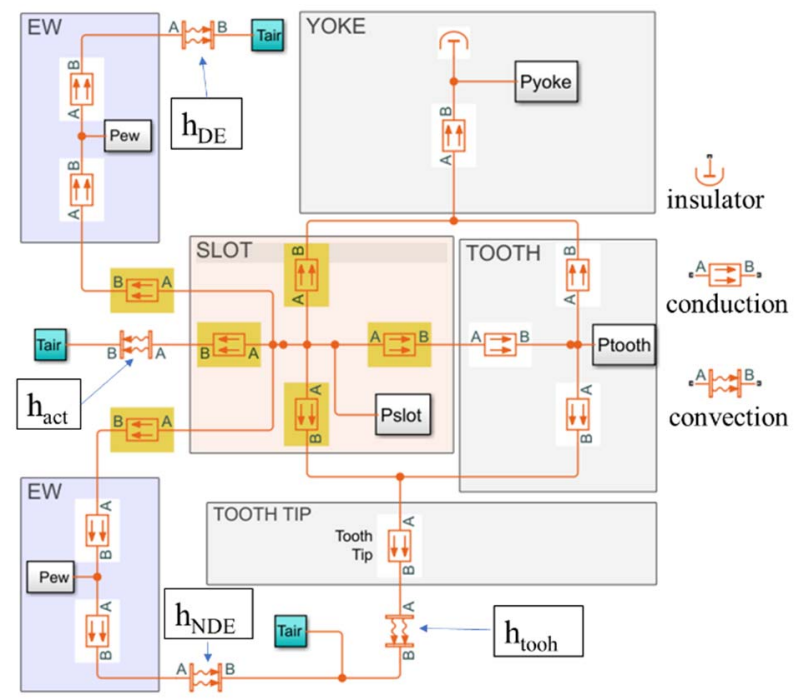

Fig. 7 Prototype B LPTN which considers radial and axial heat transfer.

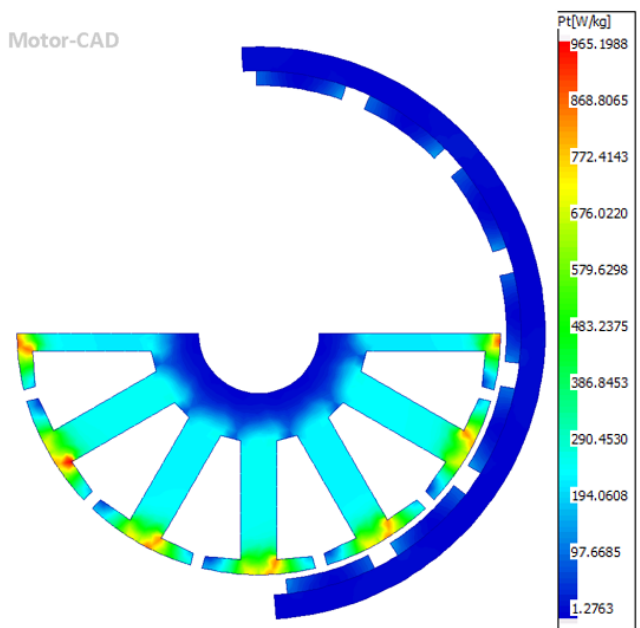

Fig. 8 Prototype B core and PMs power loss per unit weight. 


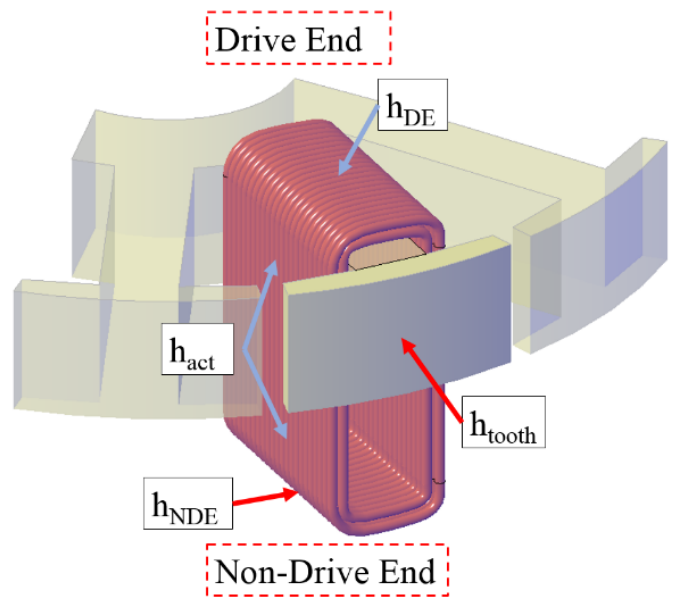

Fig. 9 Forced air-cooled surfaces.

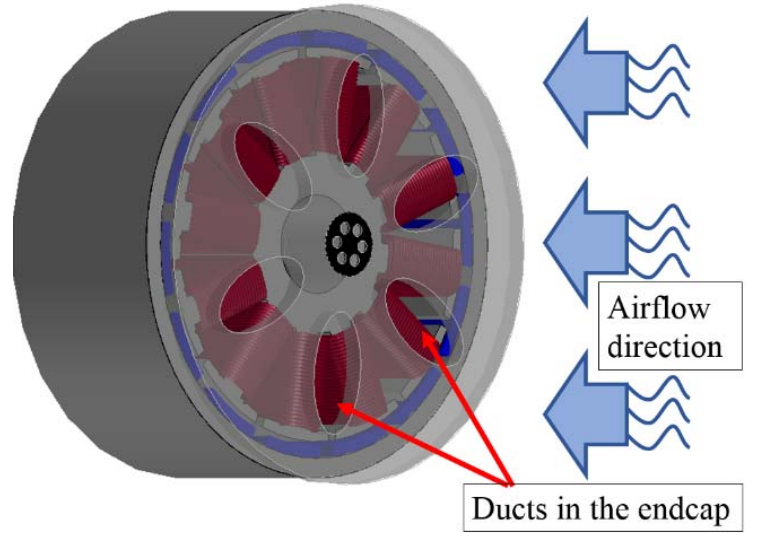

Fig. 10 Prototype B 3D view including end cap.

Given the complex airflow distribution, it is relatively complicated to analytically determine the forced convection coefficients. For this reason, a computational fluid dynamic (CFD) simulation has been performed for completing the aforementioned task. The air-velocity pathline plot for the EM's internal air, obtained with ANSYS ${ }^{\circledR}$ Fluent, is reported in Fig. 11. For this simulation, it has been assumed that the airflow entering the front end cap has a velocity of $28 \mathrm{~m} / \mathrm{s}$ (i.e. UAV cruising at $\approx 100 \mathrm{~km} / \mathrm{h}$ ). The cross sectional area considered for the CFD simulation (i.e. AA'-BB') is the one reported in Fig. 12.

As outcome of the CFD analysis, the (surface average) convection heat transfer coefficients have been calculated and they are listed in Table II. The $h_{\text {tooth }}$ was not computed through CFD and its value has been assumed conservatively equal to $\mathrm{h}_{\mathrm{act}}$.

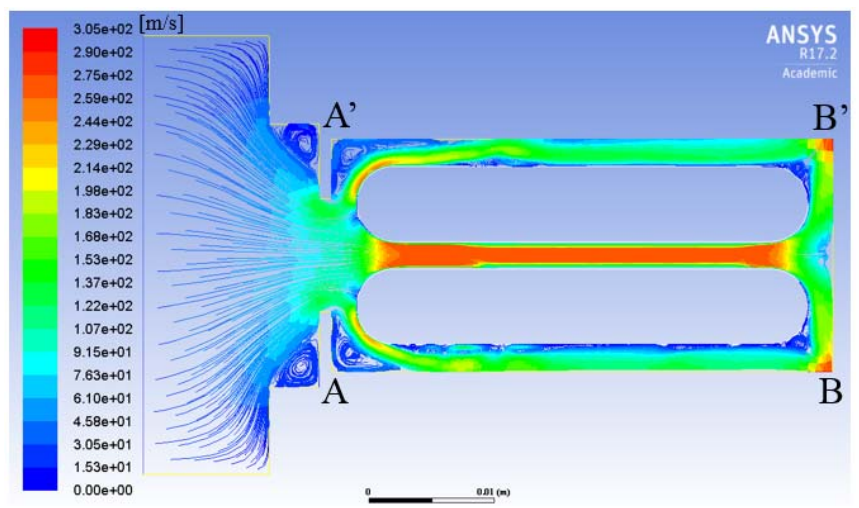

Fig. 11 Prototype B air velocity pathline plot computed with ANSYS ${ }^{\circledR}$ Fluent.

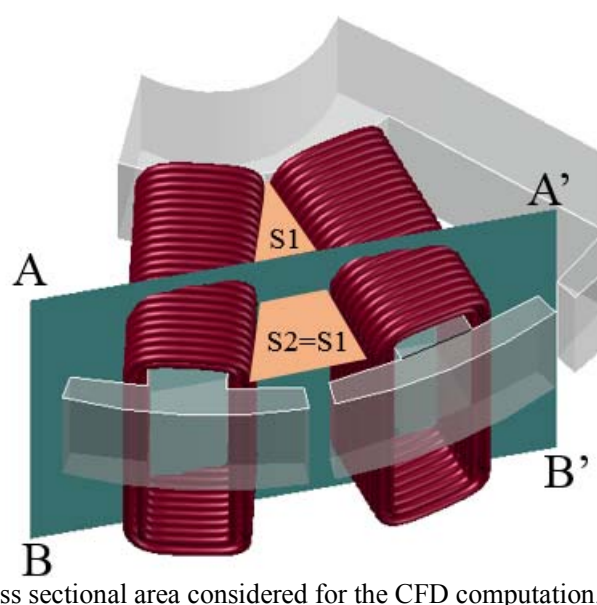

Fig. 12 Cross sectional area considered for the CFD computation.

TABLE II CONVECTION HEAT TRANSFER COEFFICIENTS FROM CFD

\begin{tabular}{cc}
\hline \hline Heat transfer coeff. & Value $\left[\mathrm{W} / \mathrm{m}^{2} / \mathrm{K}\right]$ \\
\hline $\mathrm{h}_{\mathrm{DE}}$ & 279.8 \\
\hline $\mathrm{h}_{\mathrm{NDE}}$ & 231.6 \\
\hline $\mathrm{h}_{\text {act }}$ & 104.8 \\
\hline $\mathrm{h}_{\text {tooth }}$ & 104.8 \\
\hline \hline
\end{tabular}

Since the machine is not impregnated, the windings' thermal conductivity in the radial direction is set to 1.5 $\mathrm{W} / \mathrm{m} / \mathrm{K}$, while in the axial direction it is equal to $400 \mathrm{~W} / \mathrm{m} / \mathrm{K}$ (i.e. pure copper). The heat axially flowing through the iron lamination stack is neglected, because the lamination thermal conduction coefficient in the axial direction is two orders of magnitude lower than the copper one.

The LPTN reported in Fig. 7 is employed for predicting Prototype B's temperature. Following the UAV's mission profile shown in Fig. 1, $J=18.9 \mathrm{~A} / \mathrm{mm}^{2}$ is applied for the first 60 s (i.e. take off and climbing) and then $\mathrm{J}=6.3 \mathrm{~A} / \mathrm{mm}^{2}$ is imposed until $500 \mathrm{~s}$ (i.e. cruise and descent). The thermal simulation's outcome is reported in Fig. 13, where the hot-spot temperature profile is plotted. It is possible to note that the temperature rises up-to $280{ }^{\circ} \mathrm{C}$ during the first stage of the mission and then it settles at the steady-state value of $147^{\circ} \mathrm{C}$ throughout the second part of the mission profile. The thermal profile portion, outlined in the red dashed box of Fig. 13 , is above the insulation's thermal class (i.e. $200{ }^{\circ} \mathrm{C}$ ) and it is employed for investigating the impact of thermal overload on the insulation's lifetime, as discussed in the next section.

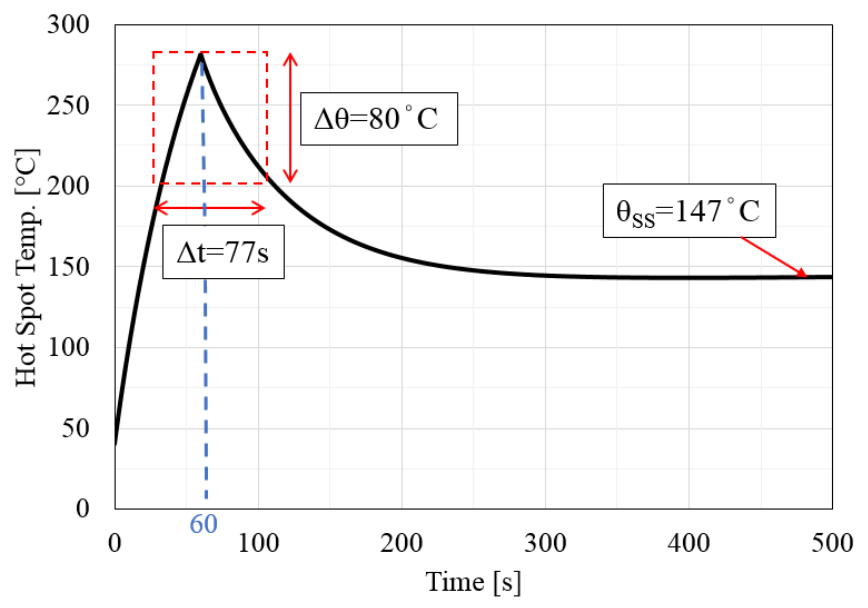

Fig. 13 LPTN-estimated hot-spot temperature during mission profile.

\section{INSULATION ACCELERATED LIFETIME TESTS}

Because of the thermal overload, the Prototype's B compliance to the reliability constraint is experimentally 
verified by means of accelerated aging tests. As the hot-spot is located in the machine's windings, the weakest insulation subsystem is represented by the turn-to-turn enamel layer [31, 32]. A total of 12 coils (i.e. specimens) have been wound adopting a Grade 2, class 200, $0.4 \mathrm{~mm}$ diameter magnet wire (i.e. the same wire used for both prototypes). Each coil consists of 20 turns with 2 strands, so that the interturn insulation (i.e. strand-to-strand) status can be assessed. The specimens are thermally aged by the cyclic application of the temperature profile reported in the red dashed box of Fig. 13. Hence, the series-connected coils are fed via a programmable DC power source and they are inserted inside a fume hood with a variable airflow, for safety reasons. The highlighted temperature profile is obtained by selecting a suitable combination of DC current and airflow. The interturn insulation status is assessed every 24 hours through the measurement of the insulation capacitance (IC) and dissipation factor (i.e. $\tan \delta$ ) using a Megger ${ }^{\circledR}$ Delta 4000. The complete test rig is illustrated in Fig. 14, whereas the testing procedure flowchart is outlined in Fig. 15. The interturn dielectric breakdown is chosen as end of life criterion for the aged coils, and it is detected via the Megger. The latter applies a sinusoidal voltage, whose amplitude is ramped-up from 0 to 500 Vrms during the diagnostic process. In case of specimen failure, the coil is removed from the thermal exposure and the time to failure is recorded.

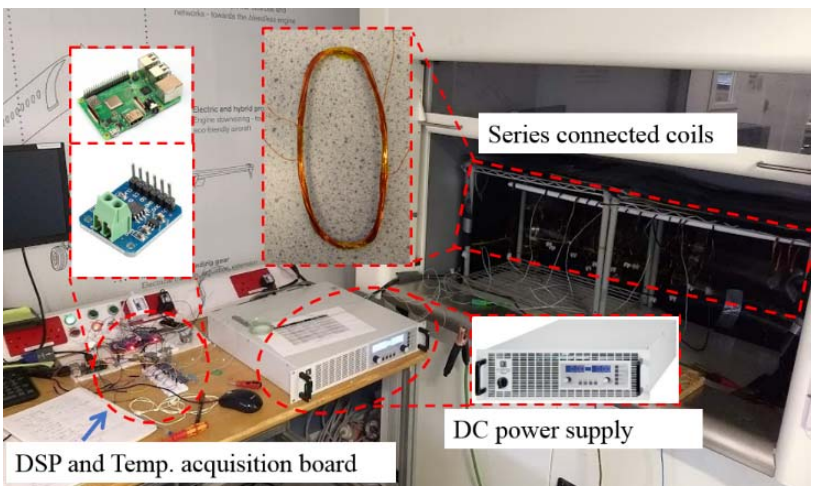

Fig. 14 Test bench adopted during the accelerated aging tests.

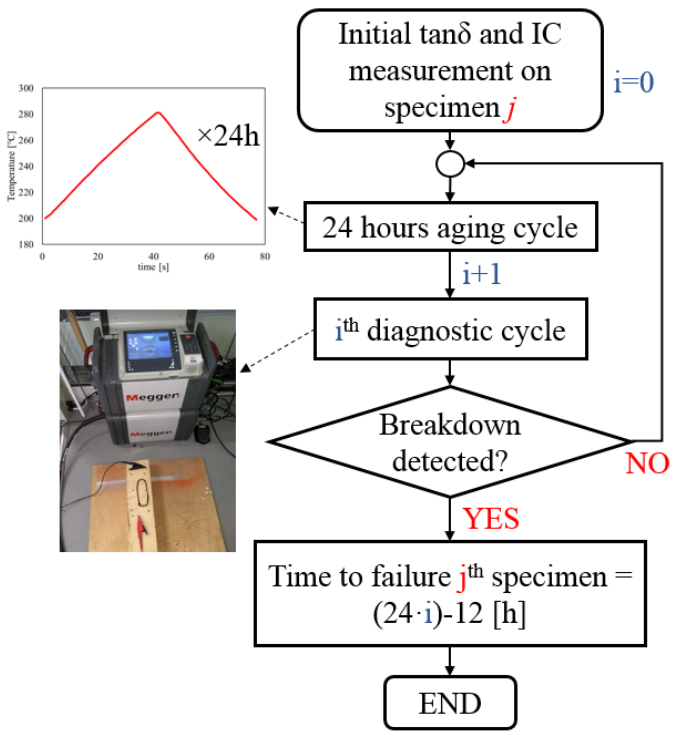

Fig. 15 Flow chart of the testing procedure.

The collected data are post-processed via the 2-parameters Weibull distribution, which is a statistical tool widely adopted in accelerated lifetime tests [33, 34]. The derived Weibull probability plot, with $95 \%$ confidence intervals, is shown in
Fig. 16, where only the average of tied points is reported, for representation clarity.

Considering Fig. 16, the 1\% percentile of the Weibull distribution, corresponds to 8,360 cycles to failure (i.e. UAV missions). Therefore, Prototype $\mathrm{B}$ fulfills the reliability requirement (i.e. $5000+$ missions) and a wide safety margin is secured.

For completeness, the survival function plot is provided in Fig. 17. Despite the significant thermal stress, the survival probability is still above $95 \%$ after 10,000 overload cycles.

It is worth to remark that the selected end of life criterion is highly conservative, since a voltage up-to $500 \mathrm{Vrms}$ is applied to the aged coils. This approach compensates for having overlooked other insulation stressing factors (e.g. mechanical vibrations) in the introduced study.

Based on the presented results, the application's power requirements can be achieved adopting a machine whose axial length is $33 \%$ shorter than the original design, as highlighted in Fig. 18. The 33\% axial length reduction also leads to a $31.6 \%$ weight contraction. In fact, Prototype A active weight is equal to $0.308 \mathrm{~kg}$ against the $0.211 \mathrm{~kg}$ of Prototype B.

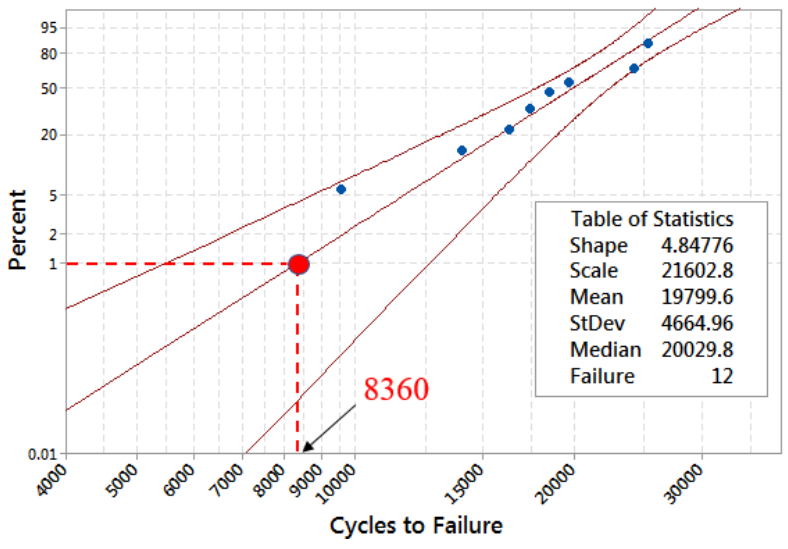

Fig. 16 Weibull probability plot of the specimens' time to failure.

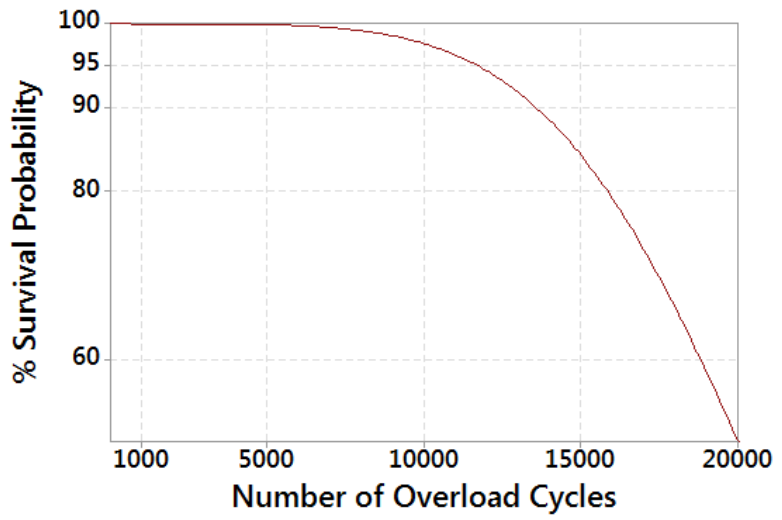

Fig. 17 Weibull survival probability plot of the tested specimens.

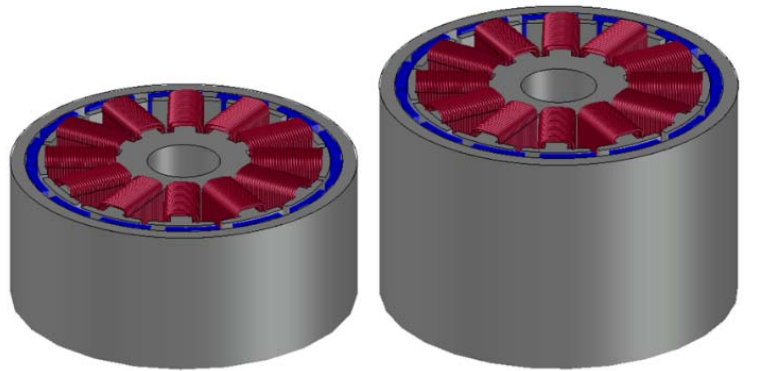

Fig. 18 3D view of the designed prototypes (left-hand side Prototype B and right-hand side Prototype A). 


\section{CONCLUSIONS}

In this paper, a novel approach for electrical machines design, based on insulation physics of failure considerations, has been presented. For a given application, it has been proved that the adoption of the proposed design methodology allows for a considerable performance enhancement. Indeed, the $31.6 \%$ weight reduction, together with the increased current density ensuing from the higher operating temperature, resulted in an excellent power density improvement for Prototype B. Considering the peak power density, Prototype A features $2.8 \mathrm{~kW} / \mathrm{kg}$, whilst Prototype B reveals $3.1 \mathrm{~kW} / \mathrm{kg}$.

The discussed study case illustrates how the introduction of reliability and physics of failure concepts, at the design stage of an electrical machine, can considerably influence the overall performance in terms of torque/power density leading to cost saving. In fact, from a cost-effective point of view, a shorter EM requires fewer active materials (e.g. PMs, copper, etc...). Considering the machines at hand, $25.6 \mathrm{~g}$ versus 17.1 $\mathrm{g}$ of PMs are needed for Prototype A and B respectively. Although this cost saving might seem tiny, a more significant cost benefit could be achieved by applying the proposed design methodology to a machine with higher power rating.

\section{REFERENCES}

[1] V. Madonna, P. Giangrande, A. Walker, and M. Galea, "On the Effects of Advanced End-Winding Cooling on the Design and Performance of Electrical Machines," in 2018 XIII International Conference on Electrical Machines (ICEM), 2018, pp. 311-317.

[2] P. Lindh et al., "Multidisciplinary Design of a Permanent-Magnet Traction Motor for a Hybrid Bus Taking the Load Cycle into Account," IEEE Transactions on Industrial Electronics, vol. 63, no. 6, pp. 33973408, 2016.

[3] M. Galea, C. Gerada, T. Raminosoa, and P. Wheeler, "A Thermal Improvement Technique for the Phase Windings of Electrical Machines," IEEE Transactions on Industry Applications, vol. 48, no. 1, pp. 79-87, 2012.

[4] P. Giangrande, V. Madonna, G. Sala, A. Kladas, C. Gerada, and M. Galea, "Design and Testing of PMSM for Aerospace EMA Applications," in IECON 2018 - 44th Annual Conference of the IEEE Industrial Electronics Society, 2018, pp. 2038-2043.

[5] M. Galea, L. Papini, H. Zhang, C. Gerada, and T. Hamiti, "Demagnetization Analysis for Halbach Array Configurations in Electrical Machines," IEEE Transactions on Magnetics, vol. 51, no. 9, pp. 1-9, 2015.

[6] Y. Gritli, D. Casadei, A. Tani, C. Rossi, and G. Serra, "Validation of Rotor Magnets Demagnetization Detection in Six-Phase SurfaceMounted AC Permanent Magnet Synchronous Motors," in 2018 International Symposium on Power Electronics, Electrical Drives, Automation and Motion (SPEEDAM), 2018, pp. 224-229.

[7] S. A. Odhano, P. Giangrande, R. Bojoi, and C. Gerada, "Selfcommissioning of interior permanent magnet synchronous motor drives with high-frequency current injection," in 2013 IEEE Energy Conversion Congress and Exposition, 2013, pp. 3852-3859.

[8] V. Madonna, P. Giangrande, L. Lusuardi, A. Cavallini, and M. Galea, "Impact of thermal overload on the insulation aging in short duty cycle motors for aerospace," in 2018 IEEE ESARS-ITEC, 2018, pp. 1-6.

[9] D. Barater et al., "Multistress Characterization of Fault Mechanisms in Aerospace Electric Actuators," IEEE Transactions on Industry Applications, vol. 53, no. 2, pp. 1106-1115, 2017.

[10] C. Sciascera, M. Galea, P. Giangrande, and C. Gerada, "Lifetime consumption and degradation analysis of the winding insulation of electrical machines," in 8th IET International Conference on Power Electronics, Machines and Drives (PEMD 2016), 2016, pp. 1-5.

[11] P. Giangrande, V. Madonna, S. Nuzzo, and M. Galea, "Design of FaultTolerant Dual Three-Phase Winding PMSM for Helicopter Landing Gear EMA," presented at the 2018 IEEE ESARS-ITEC, Nottingham UK, 2018.

[12] D. L. Gabriel, J. Meyer, and F. d. Plessis, "Brushless DC motor characterisation and selection for a fixed wing UAV," in IEEE Africon '11, 2011, pp. 1-6.

[13] P. Yedamale, "Brushless DC (BLDC) motor fundamentals," Microchip Technology Inc, vol. 20, pp. 3-15, 2003
[14] R. Glassock, M. Galea, W. Williams, and T. Glesk, "Hybrid Electric Aircraft Propulsion Case Study for Skydiving Mission," Aerospace. 2017; 4(3):45, 2017.

[15] R. Glassock, M. Galea, W. Williams, and T. Glesk, "Novel Hybrid Electric Aircraft Propulsion Case Studies," Aeronautics and Astronautics, MDPI Journal on, vol. vol. 4, iss. 3, article 45, 2017.

[16] F. Cupertino, P. Giangrande, L. Salvatore, and G. Pellegrino, "Model based design of a sensorless control scheme for permanent magnet motors using signal injection," in 2010 IEEE Energy Conversion Congress and Exposition, 2010, pp. 3139-3146.

[17] A. Damiano et al., "Batteries for Aerospace: a Brief Review," in 2018 AEIT International Annual Conference, 2018, pp. 1-6.

[18] V. Madonna, P. Giangrande, and M. Galea, "Electrical Power Generation in Aircraft: Review, Challenges, and Opportunities," IEEE Transactions on Transportation Electrification, vol. 4, no. 3, pp. 646659, 2018.

[19] C. I. Hill, S. Bozhko, Y. Tao, P. Giangrande, and C. Gerada, "More Electric Aircraft Electro-Mechanical Actuator Regenerated Power Management," in 2015 IEEE 24th International Symposium on Industrial Electronics (ISIE), 2015, pp. 337-342.

[20] C. Sciascera, P. Giangrande, C. Brunson, M. Galea, and C. Gerada, "Optimal design of an electro-mechanical actuator for aerospace application," in IECON 2015 - 41st Annual Conference of the IEEE Industrial Electronics Society, 2015, pp. 001903-001908.

[21] A. Al-Timimy, G. Vakil, M. Degano, P. Giangrande, C. Gerada, and M. Galea, "Considerations on the Effects That Core Material Machining Has on an Electrical Machine's Performance," IEEE Transactions on Energy Conversion, vol. 33, no. 3, pp. 1154-1163, 2018.

[22] T. Lee, M. Seo, Y. Kim, and S. Jung, "Motor Design and Characteristics Comparison of Outer-Rotor-Type BLDC Motor and BLAC Motor Based on Numerical Analysis," IEEE Transactions on Applied Superconductivity, vol. 26, no. 4, pp. 1-6, 2016.

[23] A. Al-Timimy, P. Giangrande, M. Degano, M. Galea, and C. Gerada, "Investigation of AC Copper and Iron Losses in High-Speed HighPower Density PMSM," in 2018 XIII International Conference on Electrical Machines (ICEM), 2018, pp. 263-269.

[24] A. Boglietti, A. Cavagnino, D. Staton, M. Shanel, M. Mueller, and C. Mejuto, "Evolution and Modern Approaches for Thermal Analysis of Electrical Machines," IEEE Transactions on Industrial Electronics, vol. 56, no. 3, pp. 871-882, 2009.

[25] P. Giangrande, A. Al-Timimy, A. Galassini, S. Papadopoulos, M. Degano, and M. Galea, "Design of PMSM for EMA Employed in Secondary Flight Control Systems," in 2018 IEEE ESARS-ITEC, 2018, pp. 1-6.

[26] A. Boglietti, M. Cossale, S. Vaschetto, and T. Dutra, "Thermal Conductivity Evaluation of Fractional-Slot Concentrated-Winding Machines," IEEE Transactions on Industry Applications, vol. 53, no. 3, pp. 2059-2065, 2017.

[27] V. Madonna, P. Giangrande, C. Gerada, and M. Galea, "Thermal analysis of fault-tolerant electrical machines for more electric aircraft applications," The Journal of Engineering, vol. 2018, no. 13, pp. 461467, 2018.

[28] C. Sciascera, P. Giangrande, L. Papini, C. Gerada, and M. Galea, "Analytical Thermal Model for Fast Stator Winding Temperature Prediction," IEEE Transactions on Industrial Electronics, vol. 64, no. 8, pp. 6116-6126, 2017.

[29] V. Madonna, P. Giangrande, C. Gerada, and M. Galea, "Thermal analysis of fault-tolerant electrical machines for aerospace actuators," IET Electric Power Applications, 2018.

[30] V. Madonna, A. Walker, P. Giangrande, G. Serra, C. Gerada, and M. Galea, "Improved Thermal Management and Analysis for Stator EndWindings of Electrical Machines," IEEE Transactions on Industrial Electronics, vol. 66, no. 7, pp. 5057-5069, 2019.

[31] J. Faiz, H. Nejadi-Koti, and Z. Valipour, "Comprehensive review on inter-turn fault indexes in permanent magnet motors," IET Electric Power Applications, vol. 11, no. 1, pp. 142-156, 2017.

[32] Y. Qi, M. Zafarani, B. Akin, and S. E. Fedigan, "Analysis and Detection of Inter-Turn Short-Circuit Fault Through Extended SelfCommissioning," IEEE Transactions on Industry Applications, vol. 53, no. 3, pp. 2730-2739, 2017.

[33] L. Lusuardi, A. Cavallini, P. Mancinelli, G. D. L. C. Manuel, J. M. Martínez-Tarifa, and G. Robles, "Design criteria for inverter-fed Type 1 motors," in 2016 IEEE International Conference on Dielectrics (ICD), 2016, vol. 2, pp. 605-608.

[34] D. R. Meyer, A. Cavallini, L. Lusuardi, D. Barater, G. Pietrini, and A. Soldati, "Influence of impulse voltage repetition frequency on RPDIV in partial vacuum," IEEE Transactions on Dielectrics and Electrical Insulation, vol. 25, no. 3, pp. 873-882, 2018. 